\title{
Dietary supplementation usage by pregnant women in Silesia - population based study
}

\author{
Anna Knapik ${ }^{1}$, Krzysztof Kocot ${ }^{1}$, Andrzej Witek ${ }^{2}$, Mateusz Jankowski ${ }^{1}$, \\ Agnieszka Wróblewska-Czech², Małgorzata Kowalska ${ }^{1}$, Jan Eugeniusz Zejda ${ }^{1}$, Grzegorz Brożek ${ }^{1}$ \\ ${ }^{1}$ Department of Epidemiology, School of Medicine in Katowice, Medical University of Silesia in Katowice, Katowice, Poland \\ ${ }^{2}$ Department of Obstetrics and Gynecology, School of Medicine in Katowice, Medical University of Silesia in Katowice, Katowice, Poland
}

\begin{abstract}
Objectives: Despite wide access to gynecological and obstetric advice, informational campaigns, and information online and in magazines aimed at pregnant women, there is a worryingly high percentage of women who still do not use recommended dietary supplementation. The aim of this study was to assess the frequency of micronutrient supplementation by pregnant women and to specify the determinants that impact decisions concerning supplementation.

Material and methods: A cross-sectional survey was conducted between June 2016 and May 2017 among a group of pregnant women visiting gynecological and obstetric clinics in the Silesia region, who have completed an authorized questionnaire developed for the purpose of this study. The questionnaire addressed the women's dietary habits, micronutrient supplementation use, as well as their socio-economic status. Completed questionnaires were obtained from 505 pregnant women.

Results: Microminerals and vitamins supplementation during pregnancy was declared by 410 (81.2\%) women. The most often used supplement was folic acid (62\%). More than one-third of pregnant women (38.4\%) declared vitamin D intake. Among the recommended supplements, the least commonly used (30.3\%) were polyunsaturated fatty acids (PUFA). Factors contributing to supplementation use during pregnancy are past history of miscarriage and socioeconomic factors, such as: place of residence, financial situation and level of education. Inhabitants of larger cities, women with better self-perceived financial situations, higher education levels and those presenting past history of miscarriage took the supplements significantly more often.
\end{abstract}

Conclusions: Lower levels of education, low-income financial status and living in rural localities are among the factors correlating with worse adherence to supplementation guidelines.

Key words: dietary supplements, supplementation, pregnancy, nourishment

Ginekologia Polska 2018; 89, 9: 506-512

\section{INTRODUCTION}

The Polish Society of Gynecologists and Obstetricians recommend the supplementation of folic acid, vitamin D, iodine and PUFA to all women planning to become pregnant as well as those who are pregnant or breastfeeding [1]. Nevertheless, despite the wide access to gynecological and obstetric advice as well as informational campaigns and the distribution of information online and in magazines aimed at pregnant women, there is a worryingly high percentage of women who still do not use neither proper supplementation nor maintain a balanced diet during preg- nancy. National data has shown that the use of supplements are still neglected $[2,3]$. Other studies carried out in various countries worldwide clearly demonstrate that mistakes in diet and supplementation are a global health problem [4-8]. There are many factors that may have impact on the decision to take supplements during pregnancy, among them socio-economic status, place of residence and level of education are often highlighted [4-7, 9]. Contact with health professionals is often mentioned as a major source of knowledge about supplementation and as the determinant of whether a woman will adhere to supplementation 
guidelines [5-7]. Better understanding of the factors relating to the use of dietary supplements in Poland may be beneficial in identifying women who are at a higher risk of micronutrient deficiency during pregnancy.

\section{OBJECTIVES}

The aim of this study was to assess the frequency of micronutrient supplementation by pregnant women and to specify the determinants that impact decisions concerning supplementation, with the aim of identifying groups of women who are particularly prone to the occurrence of micronutrient deficiencies.

\section{MATERIAL AND METHODS}

A cross-sectional survey was conducted between June 2016 and May 2017. The study group consisted of pregnant women attending gynecological and obstetric clinics in the Silesia region, who completed an authorised questionnaire prepared for the purpose of the study. The questionnaire included 37 questions related to the dietary habits and micronutrient supplementation during pregnancy. The questions also addressed socio-economic status, course of pregnancy, quality and amount of eaten meals as well as used stimulants. Additionally, questions assessing main sources of knowledge about proper nutrition in pregnancy and whether the decision to supplement was taken after the consultation with a health professional were included. The composition of multivitamin and multimineral supplements provided in the questionnaire was analysed with the use of professional drugs and supplements databases. The questionnaire was previously validated in a pilot study where 54 women completed the survey twice, two days apart. Depending on the question and subscale, Cronbach's alpha ranged between 0.72-0.92, the kappa coefficient ranged from 0.62 to 0.95 . Participation in the study was voluntary and anonymous. Completed questionnaires were obtained from 505 pregnant women (response rate: $84 \%$ ).

Subjects were classified into one of three groups based on their place of residence: rural, cities up to 100,000 residents, or cities above 100,000 residents. Depending on the material status, the following groups were separated: people with unsatisfactory, moderate or satisfactory financial situation. In regards to education level, women with higher education and those without higher education were distinguished. The data was analyzed with SAS 9.4 Software (SAS Institute Inc., USA). Normality of distributions of continuous variables was assessed by the Shapiro-Wilk test. Statistical significance of differences between continuous variables were analysed by the independent samples t-test or the Mann-Whitney $U$ test, if the assumptions for the t-test were not met. Distribution of categorical variables were shown by frequencies and proportions along with $95 \%$ confidence intervals. Statistical testing to compare between categorical variables was completed using the independent samples chi-square test. Multivariable analysis was done using logistic regression procedure for the variables with statistically significant differences between groups. Statistical inference was based on the criterion $\mathrm{p}<0.05$.

\section{RESULTS}

The average age of the respondents was $29.6 \pm 5.3$ years (range 16-44). Half of the group were primigravidas (i.e. had not been pregnant before). Most of the women were in a single pregnancy (92.3\%), 6.3\% of the respondents declared plural pregnancy and $1.4 \%$ were unable to determine the multiplicity of pregnancies. An earlier miscarriage was declared by $13.6 \%$ of women. In a multiple-choice question, women were asked to name their main source of knowledge about proper nutrition during pregnancy. The result of this question revealed that most women indicated the Internet (61\%) and medical staff - either doctor or midwife - (56\%) was their main source of knowledge about pregnancy. Other detailed characteristics of qualitative variables are presented in Table 1.

Microminerals and vitamins supplementation during pregnancy was declared by $410(81.2 \%)$ of women. The most often used supplement was folic acid (62\%). More than one-third of pregnant women (38.4\%) declared vitamin D intake. Among the recommended supplements, the least commonly used (24.6\%) were polyunsaturated fatty acids (PUFA).

The largest proportion of supplementation use by women was among: citizens of urban areas, those whose source of knowledge was the Internet, those who were better educated, those who indicated a satisfactory financial situation and those with history of a miscarriage in the past. Detailed data are presented in Table 2 .

Results of multivariable analysis confirmed (Tab. 3) that pregnant women who are better educated and those with earlier miscarry show a statistically significant increased rate of supplementation use. Moreover, the factor significantly associated with supplementation is the higher financial status of family.

\section{DISCUSSION}

The Polish Society of Gynecologists recommends supplementation of folic acid, vitamin D and iodine for all pregnant women. Other beneficial substances, which should be used depending on the risk of shortages, are: iron, magnesium and polyunsaturated omega-3 fatty acids (especially DHA — docosahexaenoic acid) [1].

Our study shows that the utilization of the aforementioned supplements among pregnant women is still unsatisfactory. The largest proportion of women supplemented folic acid, and the smallest PUFA: $62 \%$ and $24.6 \%$, respec- 
Table 1. Characteristics of the study population

\begin{tabular}{|c|c|}
\hline Total group $n=505(100 \%)$ & Percentage (95\% Cl) \\
\hline \multicolumn{2}{|l|}{ Place of residence } \\
\hline Rural & $23.5 \%(19.9-27.3)$ \\
\hline City up to 100,000 residents & $30.3 \%(26.4-34.4)$ \\
\hline City above 100,000 residents & $46.2 \%(41.8-50.5)$ \\
\hline \multicolumn{2}{|l|}{ Education } \\
\hline Non-higher & $41 \%(36.8-45.3)$ \\
\hline Higher & $59 \%(54.7-63.2)$ \\
\hline \multicolumn{2}{|l|}{ Financial situation } \\
\hline Unsatisfactory & $9.4 \%(7.2-12.4)$ \\
\hline Moderate & $36.7 \%(32.5-40.9)$ \\
\hline Satisfactory & $53.9 \%(49.5-58.2)$ \\
\hline \multicolumn{2}{|l|}{ Working status } \\
\hline Active worker & $84.4 \%(80.9-87.4)$ \\
\hline Unemployed & $15.6 \%(12.6-19.1)$ \\
\hline \multicolumn{2}{|l|}{ Pregnancy history } \\
\hline Primigravidas & $50.1 \%(45.7-54.4)$ \\
\hline Multiparous & $49.9 \%(45.6-54.3)$ \\
\hline \multicolumn{2}{|l|}{ Earlier miscarriage $(n=212)$} \\
\hline Yes & $25.9 \%(20.5-32.2)$ \\
\hline No & $74.1 \%(67.8-79.5)$ \\
\hline \multicolumn{2}{|c|}{ Have you used supplementation during your current pregnancy? } \\
\hline Yes & $81.2 \%(77.6-84.4)$ \\
\hline No & $18.8 \%(15.6-22.5)$ \\
\hline \multicolumn{2}{|c|}{ Source of knowledge about proper nutrition during pregnancy } \\
\hline Internet & $61 \%(57-65)$ \\
\hline Health practitioners & $56 \%(52-61)$ \\
\hline Thematic press & $40 \%(36-45)$ \\
\hline Other & $6 \%(5-9)$ \\
\hline
\end{tabular}

95\% $\mathrm{Cl}-95 \%$ confidence interval

tively. Statistical analysis showed that factors contributing to supplementation use during pregnancy are past history of miscarriage and socioeconomic factors, such as: place of residence, financial situation and level of education. In general, inhabitants of larger cities, women with a better self-perceived financial situation, women with a higher education level and those presenting past history of miscarriage took the supplements significantly more often. According to the results of multivariate logistic regression analysis, past history of miscarriage turned out to be the only determinant significant for all of the studied supplements. Higher education was valid for all supplements, apart from folic acid. Living in larger cities (above 100,000 inhabitants) was a significant determinant of taking iodine and magnesium, while having an improved financial status was a determinant of whether PUFA, iron and vitamin D were taken. At the same time being an active worker showed no relation to supplement usage. The decision on supplementation was most frequently taken after the consultation with health professionals, while Internet was mentioned as the main source of knowledge about supplementation in pregnancy by the largest proportion of participants.

The need for dietary supplementation during pregnancy has been well studied and confirmed. Folate deficiency is strongly correlated with neural tube defects (NTD) in the fetus, but it may also contribute to poor fetal development and higher incidence of small for gestational age (SGA) in neonates, as well as preeclampsia in mothers [1, 10-12]. Vitamin D is involved with proper bone mineralization, assisting in the regulation of gene transcription and playing a crucial role in the modulatory role in the immunological system [1]. Its deficiency may lead to hypocalcemia and an increased 
Table 2. Frequency of micronutrients supplementation depending on socioeconomic factors and past history of miscarriage

\begin{tabular}{|c|c|c|c|c|c|c|}
\hline & $\begin{array}{l}\text { Folic acid } \\
\%(95 \% \mathrm{Cl})\end{array}$ & $\begin{array}{l}\text { PUFA } \\
\%(95 \% \mathrm{Cl})\end{array}$ & $\begin{array}{l}\text { Iron } \\
\%(95 \% \mathrm{Cl})\end{array}$ & $\begin{array}{l}\text { lodine } \\
\%(95 \% \mathrm{Cl})\end{array}$ & $\begin{array}{l}\text { Vitamin D } \\
\%(95 \% \mathrm{Cl})\end{array}$ & $\begin{array}{l}\mathrm{Mg} \\
\%(95 \% \mathrm{Cl})\end{array}$ \\
\hline Total $n=505(100 \%)$ & $62.0 \%(57.7-66.1)$ & $24.6 \%(21.0-28.5)$ & $34.9 \%(30.8-39.1)$ & $34.5 \%(30.4-38.7)$ & $38.4 \%(34.1-42.5)$ & $28.3 \%(24.6-32.4)$ \\
\hline \multicolumn{7}{|c|}{ Place of residence $n=502(100 \%)$} \\
\hline Rural $n=118(23.5 \%)$ & $49 \%(40.3-58.0)$ & $12.7 \%(7.9-19.9)$ & $22 \%(15.5-30.3)$ & $21.2 \%(14.8-29.4)$ & $28.8 \%(21.4-37.6)$ & $18.6 \%(12.7-26.6)$ \\
\hline $\begin{array}{l}\text { Cities up to } \\
100,00 \text { citizens } \\
N=152(30.3 \%)\end{array}$ & $\begin{array}{l}63.2 \% \\
(55.3-70.4)\end{array}$ & $\begin{array}{l}26.3 \% \\
(20.0-33.8)\end{array}$ & $\begin{array}{l}35.5 \% \\
(28.4-43.4)\end{array}$ & $\begin{array}{l}34.8 \% \\
(27.8-42.7)\end{array}$ & $\begin{array}{l}37.5 \% \\
(30.2-45.4)\end{array}$ & $\begin{array}{l}25 \% \\
(18.8-32.4)\end{array}$ \\
\hline $\begin{array}{l}\text { Cities above } \\
100,00 \text { citizens } \\
n=232(46.2 \%)\end{array}$ & $\begin{array}{l}67.2 \% \\
(61.0-73.0)\end{array}$ & $\begin{array}{l}29.7 \% \\
(24.2-35.9)\end{array}$ & $\begin{array}{l}41 \% \\
(34.8-47.4)\end{array}$ & $\begin{array}{l}40.5 \% \\
(34.4-46.9)\end{array}$ & $\begin{array}{l}43.5 \% \\
(37.3-50.0)\end{array}$ & $\begin{array}{l}35.8 \% \\
(29.9-42.1)\end{array}$ \\
\hline $\mathrm{P}$ & 0.004 & 0.002 & 0.002 & 0.001 & 0.02 & 0.001 \\
\hline \multicolumn{7}{|c|}{ Source of knowledge - Internet $n=505(100 \%)$} \\
\hline Yes $n=309(61.2 \%)$ & $64.4 \%(58.9-69.5)$ & $26.2 \%(21.6-31.4)$ & $38.8 \%(21.6-31.4)$ & $37.5 \%(32.3-43.1)$ & $41.8 \%(32.3-43.1)$ & $30.4 \%(25.6-35.8)$ \\
\hline No $n=196(38.8 \%)$ & $58.2 \%(51.2-64.9)$ & $21.9 \%(16.7-28.2)$ & $28.6 \%(22.7-35.3)$ & $29.6 \%(23.6-36.3)$ & $33.2 \%(27-40)$ & $25 \%(19.5-31.5)$ \\
\hline$P$ & 0.16 & 0.28 & 0.02 & 0.07 & 0.05 & 0.19 \\
\hline \multicolumn{7}{|c|}{ Source of knowledge - doctor/midwife $n=505(100 \%)$} \\
\hline Yes $n=285(56.4 \%)$ & $61.4 \%(55.6-66.9)$ & $26.7 \%(21.9-32.1)$ & $34.7 \%(29.5-40.4)$ & $31.2 \%(26.1-36.8)$ & $35.4 \%(30.1-41.2)$ & $26.7 \%(21.9-32.1)$ \\
\hline No $n=220(43.6 \%)$ & $62.7 \%(56.2-68.9)$ & $21.8 \%(16.9-27.7)$ & $35 \%(29-41.5)$ & $38.6 \%(32.5-45.2)$ & $42.3 \%(35.9-48.9)$ & $30.5 \%(24.8-36.8)$ \\
\hline$P$ & 0.76 & 0.21 & 0.95 & 0.08 & 0.12 & 0.35 \\
\hline \multicolumn{7}{|c|}{ Financial status $n=414(100 \%)$} \\
\hline $\begin{array}{l}\text { Unsatisfactory } \\
n=39(9.4 \%)\end{array}$ & $59 \%(43.4-72.9)$ & $5.1 \%(1.4-16.9)$ & $12.8 \%(5.6-26.7)$ & $12.8 \%(5.6-26.7)$ & $12.8 \%(5.6-26.7)$ & $12.8 \%(5.6-26.7)$ \\
\hline $\begin{array}{l}\text { Moderate } \\
n=152(36.7 \%)\end{array}$ & $\begin{array}{l}57.2 \% \\
(49.3-64.8)\end{array}$ & $\begin{array}{l}17.1 \% \\
(12-23.9)\end{array}$ & $\begin{array}{l}38.8 \% \\
(31.4-46.8)\end{array}$ & $\begin{array}{l}33 \% \\
(25.9-40.7)\end{array}$ & $\begin{array}{l}36.8 \% \\
(29.6-44.8)\end{array}$ & $\begin{array}{l}28.3 \% \\
(21.7-35.9)\end{array}$ \\
\hline $\begin{array}{l}\text { Satisfactory } \\
n=223(53.9 \%)\end{array}$ & $\begin{array}{l}66.8 \% \\
(60.4-72.7)\end{array}$ & $\begin{array}{l}31.4 \% \\
(25.7-37.8)\end{array}$ & $\begin{array}{l}37.7 \% \\
(31.6-44.2)\end{array}$ & $\begin{array}{l}39 \% \\
(32.9-45.6)\end{array}$ & $\begin{array}{l}44 \% \\
(37.6-50.5)\end{array}$ & $\begin{array}{l}31 \% \\
(25.2-37.3)\end{array}$ \\
\hline $\mathrm{P}$ & 0.1 & 0.0001 & 0.007 & 0.005 & 0.001 & 0.02 \\
\hline \multicolumn{7}{|c|}{ Education level $n=397(100 \%)$} \\
\hline $\begin{array}{l}\text { Non-higher degree } \\
n=145(36.5 \%)\end{array}$ & $\begin{array}{l}77.2 \% \\
(69.8-83.3)\end{array}$ & $\begin{array}{l}17.9 \% \\
(12.5-25.0)\end{array}$ & $\begin{array}{l}32.4 \% \\
(25.3-40.4)\end{array}$ & $\begin{array}{l}31.7 \% \\
(24.7-39.7)\end{array}$ & $\begin{array}{l}33.8 \% \\
(26.6-41.8)\end{array}$ & $\begin{array}{l}24.8 \% \\
(18.5-32.5)\end{array}$ \\
\hline $\begin{array}{l}\text { Higher education } \\
\mathrm{n}=252(63.5 \%)\end{array}$ & $\begin{array}{l}74.6 \% \\
(68.9-79.6)\end{array}$ & $\begin{array}{l}36.5 \% \\
(30.8-42.6)\end{array}$ & $\begin{array}{l}47.2 \% \\
(41.2-53.4)\end{array}$ & $\begin{array}{l}47.2 \% \\
(41.2-53.4)\end{array}$ & $\begin{array}{l}53.2 \% \\
(47.0-59.2)\end{array}$ & $\begin{array}{l}39.3 \% \\
(33.5-45.4)\end{array}$ \\
\hline$P$ & 0.5 & 0.0001 & 0.004 & 0.002 & 0.0002 & 0.003 \\
\hline \multicolumn{7}{|c|}{ Working status $n=482(100 \%)$} \\
\hline $\begin{array}{l}\text { Unemployed } \\
n=75(15.6 \%)\end{array}$ & $\begin{array}{l}53.3 \% \\
(42.2-64.2)\end{array}$ & $\begin{array}{l}16 \% \\
(9.4-25.9)\end{array}$ & $\begin{array}{l}30.7 \% \\
(21.4-41.8)\end{array}$ & $\begin{array}{l}26.7 \% \\
(18.0-37.6)\end{array}$ & $\begin{array}{l}26.7 \% \\
(18.0-37.6)\end{array}$ & $\begin{array}{l}22.7 \% \\
(14.7-33.3)\end{array}$ \\
\hline $\begin{array}{l}\text { Active worker } \\
n=407 \text { (84.4\%) }\end{array}$ & $\begin{array}{l}63.9 \% \\
(59.1-68.4)\end{array}$ & $\begin{array}{l}25.8 \% \\
(21.8-30.3)\end{array}$ & $\begin{array}{l}35.4 \% \\
(30.9-40.1)\end{array}$ & $\begin{array}{l}35.9 \% \\
(31.4-40.6)\end{array}$ & $\begin{array}{l}40.3 \% \\
(35.6-45.1)\end{array}$ & $\begin{array}{l}28.8 \% \\
(24.6-33.3)\end{array}$ \\
\hline$P$ & 0.08 & 0.07 & 0.43 & 0.12 & 0.03 & 0.28 \\
\hline \multicolumn{7}{|c|}{ Pregnancy history $n=505(100 \%)$} \\
\hline $\begin{array}{l}\text { Primigravidas } \\
n=253(50.1 \%)\end{array}$ & $\begin{array}{l}62.9 \% \\
(56.7-68.6)\end{array}$ & $\begin{array}{l}23.7 \% \\
(18.9-29.3)\end{array}$ & $\begin{array}{l}32.8 \% \\
(27.3-38.8)\end{array}$ & $\begin{array}{l}32.8 \% \\
(27.3-38.8)\end{array}$ & $\begin{array}{l}36.0 \% \\
(30.3-42.1)\end{array}$ & $\begin{array}{l}28.1 \% \\
(22.9-33.9)\end{array}$ \\
\hline $\begin{array}{l}\text { Multiparous } \\
n=252(49.9 \%)\end{array}$ & $\begin{array}{l}61.1 \% \\
(55.0-66.9)\end{array}$ & $\begin{array}{l}25.4 \% \\
(20.4-31.1)\end{array}$ & $\begin{array}{l}36.9 \% \\
(31.2-43.0)\end{array}$ & $\begin{array}{l}36.1 \% \\
(30.4-42.2)\end{array}$ & $\begin{array}{l}40.9 \% \\
(35.0-47.0)\end{array}$ & $\begin{array}{l}28.6 \% \\
(23.4-34.4)\end{array}$ \\
\hline$P$ & 0.7 & 0.7 & 0.3 & 0.4 & 0.3 & 0.9 \\
\hline \multicolumn{7}{|c|}{ Miscarriage $n=212(100 \%)$} \\
\hline $\begin{array}{l}\text { Yes } \\
n=55(25.9 \%)\end{array}$ & $\begin{array}{l}76.4 \% \\
(63.7-85.6)\end{array}$ & $\begin{array}{l}40.0 \% \\
(28.1-53.2)\end{array}$ & $\begin{array}{l}47.3 \% \\
(34.7-60.2)\end{array}$ & $\begin{array}{l}50.9 \% \\
(38.1-63.6)\end{array}$ & $\begin{array}{l}54.6 \% \\
(41.5-67.0)\end{array}$ & $\begin{array}{l}43.6 \% \\
(31.4-56.7)\end{array}$ \\
\hline $\begin{array}{l}\text { No } \\
n=157(74.1 \%)\end{array}$ & $\begin{array}{l}53.5 \% \\
(45.7-61.1)\end{array}$ & $\begin{array}{l}18.5 \% \\
(13.2-25.3)\end{array}$ & $\begin{array}{l}31.2 \% \\
(24.5-38.8)\end{array}$ & $\begin{array}{l}30.6 \% \\
(23.9-38.2)\end{array}$ & $\begin{array}{l}34.4 \% \\
(27.4-42.1)\end{array}$ & $\begin{array}{l}24.8 \% \\
(18.7-32.2)\end{array}$ \\
\hline$P$ & 0.003 & 0.001 & 0.03 & 0.007 & 0.009 & 0.009 \\
\hline
\end{tabular}

$95 \% \mathrm{Cl}-95$ percent confidence interval; $\mathrm{P}$ - results of Chi-square test; $\mathrm{PUFA}$ - polyunsaturated fatty acids; $\mathrm{Mg}$ - magnesium 


\begin{tabular}{|c|c|c|c|c|c|c|}
\hline & Folic acid & PUFA & Iron & lodine & Vitamin D & Magnesium \\
\hline \multicolumn{7}{|l|}{ Place of residence } \\
\hline Rural & ref. & ref. & ref. & ref. & ref. & ref. \\
\hline City up to 100,000 residents & $\begin{array}{l}0.98 \\
(0.94-1.02)\end{array}$ & $\begin{array}{l}1.11 \\
(0.50-2.44)\end{array}$ & $\begin{array}{l}1.30 \\
(0.64-2.65)\end{array}$ & $\begin{array}{l}1.91 \\
(0.89-4.10)\end{array}$ & $\begin{array}{l}1.47 \\
(0.91-2.38)\end{array}$ & $\begin{array}{l}1.86 \\
(0.81-4.25)\end{array}$ \\
\hline City above 100,000 residents & $\begin{array}{l}1.38 \\
(0.67-2.85)\end{array}$ & $\begin{array}{l}1.60 \\
(0.96-1.06)\end{array}$ & $\begin{array}{l}2.00 \\
(0.92-4.34)\end{array}$ & $\begin{array}{l}2.70 \\
(1.18-6.17)\end{array}$ & $\begin{array}{l}1.78 \\
(0.83-3.79)\end{array}$ & $\begin{array}{l}2.78 \\
(1.15-6.72)\end{array}$ \\
\hline \multicolumn{7}{|l|}{ Financial situation } \\
\hline Unsatisfactory & ref. & ref. & ref. & ref. & ref. & ref. \\
\hline Moderate & $\begin{array}{l}0.79 \\
(0.37-1.69)\end{array}$ & $\begin{array}{l}2.96 \\
(0.64-13.6)\end{array}$ & $\begin{array}{l}2.79 \\
(1.10-7.91)\end{array}$ & $\begin{array}{l}2.55 \\
(0.90-7.18)\end{array}$ & $\begin{array}{l}2.95 \\
(1.09-8.29)\end{array}$ & $\begin{array}{l}2.01 \\
(0.71-5.71)\end{array}$ \\
\hline Satisfactory & $\begin{array}{l}1.07 \\
(0.48-2.36)\end{array}$ & $\begin{array}{l}4.92 \\
(1.06-22.76)\end{array}$ & $\begin{array}{l}3.65 \\
(1.29-10.31)\end{array}$ & $\begin{array}{l}2.71 \\
(0.94-7.82)\end{array}$ & $\begin{array}{l}3.11 \\
(1.09-8.91)\end{array}$ & $\begin{array}{l}1.72 \\
(0.59-5.03)\end{array}$ \\
\hline Higher education & $\begin{array}{l}1.44 \\
(0.89-2.33)\end{array}$ & $\begin{array}{l}2.90 \\
(1.51-5.55)\end{array}$ & $\begin{array}{l}2.53 \\
(1.49-4.31)\end{array}$ & $\begin{array}{l}2.40 \\
(1.40-4.10)\end{array}$ & $\begin{array}{l}2.37 \\
(1.42-3.96)\end{array}$ & $\begin{array}{l}2.31 \\
(1.32-4.06)\end{array}$ \\
\hline Active worker & $\begin{array}{l}1.15 \\
(0.62-2.12)\end{array}$ & $\begin{array}{l}1.45 \\
(0.65-3.25)\end{array}$ & $\begin{array}{l}1.60 \\
(0.82-3.13)\end{array}$ & $\begin{array}{l}1.25 \\
(0.63-2.49)\end{array}$ & $\begin{array}{l}1.02 \\
(0.52-2.02)\end{array}$ & $\begin{array}{l}0.99 \\
(0.47-2.06)\end{array}$ \\
\hline Miscarry & $\begin{array}{l}2.97 \\
(1.52-5.81)\end{array}$ & $\begin{array}{l}3.55 \\
(1.71-7.37)\end{array}$ & $\begin{array}{l}2.47 \\
(1.26-4.86)\end{array}$ & $\begin{array}{l}2.42 \\
(1.25-4.67)\end{array}$ & $\begin{array}{l}2.77 \\
(1.43-5.34)\end{array}$ & $\begin{array}{l}2.23 \\
(1.12-4.44)\end{array}$ \\
\hline
\end{tabular}

risk of preterm birth and low birth weight in neonates, as well as pre-eclampsia in pregnant women. However, recent data has shown that the impact of low levels of 25-hydroxyvitamin D during pregnancy may also contribute to development of eczema, wheezing and asthma in children [13, 14]. lodine deficiency may lead to hypothyroidism in both mother and child. In addition, it may also impair the neurological development of the child, which in extreme cases, if no treatment is initiated, could lead even to cretinism [15]. Iron deficiency, which is the most common pregnancy nutritional shortage in the world, can result in anemia in pregnant women and may cause intrauterine growth retardation, low birth weight, preterm birth, as well as late effects, resulting from intrauterine programming process, in the child [16, 17]. PUFA, especially DHA supplementation may not only lower the risk of preterm birth, but also similarly to vitamin $D$, reduces the risk of the child developing allergic diseases in the future $[18,19]$.

Despite clear recommendations, inadequate dietary supplementation in pregnancy is still an important issue as not all women follow the supplementation guidelines. Our study has shown that $62 \%$ of the respondents used folic acid. This proportion is lower than observed in similar studies conducted in Łódź (75.7\%) and in the Kielce Region (87.4\%) $[2,3]$. Research from other countries have shown that the usage of folic acid among pregnant women is lower in less wealthy countries than in wealthier countries. For example, the study performed in Pakistan showed that only 38\% of pregnant women supplemented folates, which stands in contrast to $95 \%$ supplementation in Denmark $[4,5]$.
In our research, we found that vitamin D usage was low, even though it was the second most popular micronutrient (38.4\% supplementation). In comparison, the study performed in Łódź showed that vitamin D was supplemented by a higher proportion of pregnant women (64.7\%) [20]. It is worth mentioning that data from other countries provides the evidence that low vitamin D supplementation is an international issue. Results from the EuroPrevall cohort study performed in 9 European countries showed that the usage of vitamin D specific supplements ranged from only $0.3 \%$ in Spain to $5.1 \%$ in Lithuania and multivitamin supplements from $21.7 \%$ in Spain to $87.7 \%$ in Poland [21].

In the current study, only $34.5 \%$ of respondents supplemented iodine. This proportion was lower than the $45.3 \%$ observed in Łódź and the $59 \%$ in a questionnaire study conducted in the Kraków region [22, 23]. It is worth to mention that the slight differences between studies may be partially a result of different gestational ages within study populations. The first of the mentioned studies showed that the proportion of women using iodine supplementation increased with the advancement of the pregnancy and was highest in the third trimester, whereas questionnaire study in the Kraków region was performed postpartum, on the obstetric ward [22, 23].

Data on the frequency of iron supplementation in Poland is scarce and there are substantial differences between studies. In our study, the supplementation of iron was low, reported by only $34.9 \%$ of pregnant women. Another study performed on a group of pregnant women at obstetric clinics in Warsaw showed that up to $80 \%$ of those involved in the 
study used iron supplements at any time during pregnancy [24]. In contrast, Sobek et al. observed that only $19.8 \%$ of respondents from a study based in the Podkarpacie Voivodship supplemented iron [25]. As it was mentioned before, diverse results across studies may result from factors relating to different gestational age, as the first of the mentioned questionnaires was addressed to women in the perinatal period.

PUFA turned out to be the least popular micronutrient in the studied population, used only by $24.6 \%$ of respondents. Similar results were obtained in a study performed in Kielce region, Poland (34.1\%), as well as those reported in a nationwide German survey (27.8\%). This may suggest that PUFA are not commonly known in society $[3,26]$.

Despite existing recommendations and the known positive effects of the aforementioned micronutrients, their supplementation is not popular among pregnant women. In our study, apart from folic acid, all of the micronutrients mentioned above were supplemented by less than half of respondents. Studies from various countries like Denmark, Netherlands, Poland, Romania, Turkey and Pakistan reveal that low adherence to existing guidelines on proper nutrition and supplementation during pregnancy is a global concern [3-8]. There are many factors that may contribute to a woman's adherence to nutrient supplementation during pregnancy, however most of the studies, similarly to ours, emphasize the role of socio-economic factors. Education frequently correlates with the nutritional knowledge of pregnant women. Interestingly, in our study, folic acid was the only micronutrient that was supplemented with similar frequency, regardless of the level of education of a woman. It was the most popular supplement among all pregnant women indicating that its role in pregnancy is rather well known in society. In contrast, most of the studies show that level of education is an important determinant in regards to the use of other supplements as well as folic acid use [4-7, 9, 27]. Research from Romania revealed that above average nutritional knowledge was a strong determinant of folic acid, iron and multivitamins supplementation in pregnancy [6]. Similar to our results, other studies observed that women with higher incomes used supplementation more often $[4,7,27,28]$. This fact is not a surprise, as most of supplements are not subsidized, therefore they can be a substantial financial burden on a family's budget. The financial aspect of women's adherence to supplementation guidelines can be also seen at whole country and society level, as micronutrient supplementation is more popular in wealthier countries, such as the example between Denmark and Pakistan [4, 5]. On the other hand, better financial situations are almost always correlated with higher educational level, so the impact of these two factors cannot be easily assessed independently. Place of residence is another important factor determining supplementation in pregnancy. In our study, a significant number of women living in larger cities used all recommended micronutrients more frequently in comparison to those living in rural areas. These findings are consistent with those observed in other studies within Poland and in other countries [3, 29]. An explanation for this trend may be a relationship between place of residence and financial situation. Inhabitants of larger cities not only earn more money than their rural counterparts, but they also have better access to health care units in urbanized areas. Studies report that higher utilization of antenatal care correlates with higher frequency of dietary supplements use by pregnant $[4,6]$. This fact is also reflected by our results, as women predominantly decided to use micronutrient supplementation after consulting to a doctor and/or a midwife. However, quite surprisingly, rather than health professionals, the Internet was cited as the main source of knowledge among the majority of respondents, unlike in many other studies $[4,7]$.

One of the most interesting findings of our study was the correlation of past history of miscarriage with micronutrient supplementation. An international cross-sectional study concerning mental models of pregnancy provided some insight for this fact. It revealed that women of general good health and no history of miscarriage most frequently did not perceive that they are susceptible to the negative effects of folate deficiency and more often did not use folic acid supplementation in comparison to those with health problems [30].

We are aware of the limitations of our study. First of all, our study does not provide information about the dose of the supplements used, which is an important issue. For example, the cited Danish study revealed that even though $95 \%$ of respondents reported using folate supplementation at any time during pregnancy, only $10 \%$ of them supplemented folic acid following the recommended doses and timing [5]. Studies with different approaches, measuring the exact daily vitamin consumption, prove that it is insufficient among Polish pregnant women [31]. Secondly, the stage of pregnancy was not included in the analysis, and as it was mentioned before, the proportion of women using supplements increases with the time of pregnancy [22]. Finally, we also have acknowledged that there is not a sufficient number of subjects in our study and that future study among a larger population is needed.

However, our study uses a validated questionnaire to provide high quality data derived from personal interviews with pregnant women. In addition, our study group is one of the largest in Poland studying the topic of supplementation use during pregnancy, a topic in which data are scarce. Therefore our research contributes a step towards a better understanding of this important issue.

\section{CONCLUSIONS}

Despite increasing knowledge about the importance of healthy diet with supplementation of several key micronutrients, many women still do not follow the recommendations of medical scientific boards. Lower levels of education, low-income status, lack of professional activity and living in 
rural localities are among the factors correlating with poor adherence to supplementation guidelines. Further actions aimed at the increasing women's awareness of the importance of micronutrient supplementation during pregnancy are needed. Particularly healthcare practitioners should raise awareness of the advantages of supplementation among their patients, as decisions on supplementation use are predominantly made after consultation with a doctor. However, better utilizing different types of media, especially the Internet due to its frequent use as source of knowledge, should be considered as well. Improving women's adherence to the guidelines is crucial for public health as well as confer direct positive benefits to both maternal and child health.

\section{Acknowledgements}

We are grateful to Helen Ghirmai Haile and Joshua Lawson for review of the manuscript and linguistic remarks. The study was funded by scientific grant from the Medical University of Silesia (KNW-1-024/K/7/0).

\section{REFERENCES}

1. Zespół Ekspertów Polskiego Towarzystwa Ginekologicznego. Rekomendacje Polskiego Towarzystwa Ginekologicznego w zakresie stosowania witamin i mikroelementów u kobiet planujących ciążę, ciężarnych i karmiących. Ginekol Pol. 2014; 85: 395-399, indexed in Pubmed: 24834713.

2. Godala M, Pietrzak K, Łaszek M, et al. Health behaviours of pregnant residents of Łódź. Part I. Diet and vitamin-mineral supplementation. ProblHigEpidemiol. 2012; 93 (1): 38-42.

3. Suliga E. Nutritional behaviours of pregnant women in rural and urban environments. Ann Agric Environ Med. 2015; 22 (3): 513-517, doi: 10.5604/12321966.1167725, indexed in Pubmed: 26403126.

4. Nisar YB, Dibley MJ, Mir AM. Factors associated with non-use of antenatal iron and folic acid supplements among Pakistani women: a cross sectional household survey. BMC Pregnancy Childbirth. 2014; 14: 305, doi: 10.1186/1471-2393-14-305, indexed in Pubmed: 25189220.

5. Friberg AK, Jørgensen FS. Few Danish pregnant women follow guidelines on periconceptional use of folic acid. Dan Med J. 2015; 62 (3): A5019, indexed in Pubmed: 25748861.

6. Popa AD, Niţă O, Graur (Arhire) LI, et al. Nutritional knowledge as a determinant of vitamin and mineral supplementatioxn during pregnancy. BMC Public Health. 2013; 13: 1105, doi: 10.1186/1471-2458-131105, indexed in Pubmed: 24289203.

7. Köken GN, Derbent AU, Erol O, et al. Awareness and use of folic acid among reproductive age and pregnant women. J Turk GerGynecol Assoc. 2013; 14 (2): 87-91, doi: 10.5152\%2Fjtgga.2013.81594, indexed in Pubmed: 24592081.

8. Baron R, Manniën J, teVelde SJ, et al. Socio-demographic inequalities across a range of health status indicators and health behaviours among pregnant women in prenatal primary care: a cross-sectional study. BMC Pregnancy Childbirth. 2015; 15: 261, doi: 10.1186/s12884-015-0676-Z, indexed in Pubmed: 26463046.

9. Nelson CR, Leon JA, Evans J. The relationship between awareness and supplementation: which Canadian women know about folic acid and how does that translate into use? Can J Public Health. 2014 Jan 15; 105 (1): e40-6, indexed in Pubmed: 24735696.

10. Kim MW, Ahn KH, Ryu K-J, et al. Preventive Effects of Folic Acid Supplementation on Adverse Maternal and Fetal Outcomes. Dastgiri S, ed. PLoS ONE. 2014; 9 (5): e97273, doi: 10.1371/journal.pone.0097273, indexed in Pubmed: 24842467.

11. Hodgetts VA, Morris RK, Francis A, et al. Effectiveness of folic acid supplementation in pregnancy on reducing the risk of small-for-gestational age neonates: a population study, systematic review and meta-analysis. BJOG. 2015; 122: 478-490, doi: 10.1111/1471-0528.13202, indexed in Pubmed: 25424556.
12. US Preventive Services Task Force. Folic Acid Supplementation for the Prevention of Neural Tube Defects: US Preventive Services Task Force Recommendation Statement. JAMA. 2017; 317 (2): 183-189, doi: 10.1001/jama.2016.19438, indexed in Pubmed: 28097362.

13. De-Regil LM, Palacios C, Lombardo LK, et al. Vitamin D supplementation for women during pregnancy. Cochrane Database Syst Rev. 2016; 1: CD008873, doi: 10.1002/14651858.CD008873.pub3, indexed in Pubmed: 26765344.

14. Wolsk HM, Harshfield BJ, Laranjo $\mathrm{N}$, et al. Vitamin D supplementation in pregnancy, prenatal 25(OH)D levels, race, and subsequent asthma or recurrent wheeze in offspring: Secondary analyses from the Vitamin D Antenatal Asthma Reduction Trial. J Allergy Clinlmmunol. 2017; 140 (5): 1423-1429.e5, doi: 10.1016/j.jaci.2017.01.013, indexed in Pubmed: 28285844.

15. Zimmermann MB. The effects of iodine deficiency in pregnancy and infancy. Paediatr Perinat Epidemiol. 2012; 26 (Suppl 1): 108-117, doi: 10.1111/j.1365-3016.2012.01275.x, indexed in Pubmed: 22742605.

16. Milman N, Paszkowski T, Cetin I, et al. Supplementation during pregnancy: beliefs and science. GynecolEndocrinol. 2016; 32 (7): 509-16, doi: 10.3109/09513590.2016.1149161, indexed in Pubmed: 26956254.

17. Breymann C. Iron Deficiency Anemia in Pregnancy. SeminHematol 2015; 52 (4): 339-47, doi: 10.1053/j.seminhematol.2015.07.003, indexed in Pubmed: 26404445.

18. De Giuseppe R, Roggi C, Cena H. n-3 LC-PUFA supplementation: effects on infant and maternal outcomes. Eur J Nutr. 2014; 53 (5): 1147-54, doi: 10.1007/s00394-014-0660-9, indexed in Pubmed: 2444897.

19. Miles EA, Calder PC. Maternal diet and its influence on development of allergic diseases. ClinExpAllergy. 2015; 45 (1): 63-74, doi: 10.1111/cea.12453, indexed in Pubmed: 25394813.

20. Skowrońska-Jóźwiak E, Adamczewski Z, Tyszkiewicz A, et al. Assessment of adequacy of vitamin D supplementation during pregnancy. Ann Agric Environ Med. 2014; 21 (1): 198-200, indexed in Pubmed: 24738524.

21. Oliver EM, Grimshaw KE, Schoemaker AA, et al. Dietary habits and supplement use in relation to national pregnancy recommendations: data from the EuroPrevall birth cohort. Matern Child Health J. 2014; 18 (10): 2408-2425, doi: 10.1007/s10995-014-1480-5, indexed in Pubmed: 24752313.

22. Zygmunt A, Adamczewski Z, Zygmunt A, et al. An assessment of the effectiveness of iodine prophylaxis in pregnant women--analysis in one of reference gynecological-obstetric centres in Poland. Endokrynol Pol. 2015; 66 (5): 404-411, doi: 10.5603/EP.2015.0050, indexed in Pubmed: 26457494.

23. Milewicz T, Czyżewicz M, Stochmal E, et al. Intake of iodine-containing multivitamin preparations by pregnant women from the Krakow region of Poland. Endokrynol Pol. 2011; 62 (4): 309-315, indexed in Pubmed: 21879470.

24. Wierzejska R, Jarosz $M$, Siuba $M$. Diets supplementation of pregnant women - recomendation and practice.Ginekol Położ. 2012; 7: 70-78.

25. Sobek G, Socha P, Pawelec S, et al. Assessment of knowledge of women about the need for the use of supplements during pregnancy. Stand Med Pediatr. 2017; 14: 126-135.

26. Libuda L, Stimming M, Mesch C, et al. Frequencies and demographic determinants of breastfeeding and DHA supplementation in a nationwide sample of mothers in Germany. Eur J Nutr. 2014; 53 (6): 1335-44, doi: 10.1007/s00394-013-0633-4, indexed in Pubmed: 24292819.

27. Branum AM, Bailey R, Singer BJ. Dietary Supplement Use and Folate Status during Pregnancy in the United States. J Nutr. 2013; 143 (4): 486-492, doi: 10.3945/jn.112.169987, indexed in Pubmed: 23365107.

28. Pouchieu C, Lévy R, Faure C, et al. Socioeconomic, Lifestyle and Dietary Factors Associated with Dietary Supplement Use during Pregnancy. Hawkins SM, ed. PLoS ONE. 2013; 8 (8): e70733, doi: 10.1371/journal. pone.0070733, indexed in Pubmed: 23967094.

29. Xing XY, Tao FB, Hao JH, et al. Periconceptional folic acid supplementation among women attending antenatal clinic in Anhui, China: data from a population-based cohort study. Midwifery. 2012; 28 (3): 291-7, doi: 10.1016/j.midw.2011.04.002, indexed in Pubmed: 22015219.

30. Fulford B, Macklon N, Boivin J, et al. Mental models of pregnancy may explain low adherence to folic acid supplementation guidelines: cross-sectional international survey. Eur J ObstetGynecolReprodBiol. 2014; 176: 99-103, doi: 10.1016/j.ejogrb.2014.02.011, indexed in Pubmed: 24630297.

31. Bojar I, Owoc A, Humeniuk E, et al. Inappropriate consumption of vitamins and minerals by pregnant women in Poland. Ann Agric Environ Med. 2012; 19 (2): 263-6, indexed in Pubmed: 22742798. 